\title{
Comparative Study of Different Banana Ripening Methods
}

\author{
Mulualem Azene Mebratie $^{1 *}$, Kebede Woldetsadik $^{2}$, Amare Ayalew $^{2}$ and Jema Haji ${ }^{3}$ \\ ${ }^{1}$ Department of Horticulture, College of Agriculture and Veterinary Sciences, Ambo University, \\ P.O. Box: 19, Ambo, Ethiopia \\ ${ }^{2}$ School of Plant Sciences, College of Agriculture and Environmental Sciences, Haramaya University, \\ Post Box: 138, Dire Dawa, Ethiopia \\ ${ }^{3}$ School of Agricultural Economics and Agribusiness Management, College of Agriculture and Environmental
} Sciences, Haramaya University, Post Box: 138, Dire Dawa, Ethiopia

\begin{tabular}{|c|c|}
\hline Abstract & Article Information \\
\hline \multirow{11}{*}{$\begin{array}{l}\text { Ripening is one of the most important aspects in banana postharvest handling system. A } \\
\text { study was conducted to investigate the effectiveness of ripening methods and evaluate their } \\
\text { influence on postharvest quality of banana (Musa spp. cv. Dwarf Cavendish). Banana fruits } \\
\text { were treated with ethephon and smoke as source of ethylene for ripening, and other groups } \\
\text { of fruits were kept in low density polyethylene plastic, in teff straw and in banana leaf } \\
\text { (control) for ripening without external ethylene source. Changes in physico-chemical } \\
\text { qualities, days to ripe, shelf life and fruits marketability were observed. Faster changes in } \\
\text { physico-chemical qualities were observed from smoke treated bananas followed by } \\
\text { ethephon treated ones with no significant difference in quality at fully ripe stage among } \\
\text { bananas of the two treatments. The major observed differences were that smoking induced } \\
\text { rapid ripening, fruits attaining fully ripe stage in six days, leading to a relatively reduced } \\
\text { shelf life of eight days as in the case of the control treatment while it was } 10 \text { days in the } \\
\text { case of ethephon treatment. Bananas packed in banana leaf and teff straw took longer time } \\
\text { (14 days) to attain fully ripe stage with dull yellow color development followed by bananas in } \\
\text { low density polyethylene plastic (13 days). Thus, ethephon treatment resulted in better } \\
\text { banana quality, shelf life and marketability. Smoke treatment can also be considered as a } \\
\text { simple and quick means of banana ripening in conditions where commercial ethylene } \\
\text { sources are inaccessible. Modifications to reduce high temperature from smoking could } \\
\text { improve the method with respect to maintaining better fruit shelf life. } \\
\text { Copyright@2015 STAR Journal, Wollega University. All Rights Reserved. }\end{array}$} & Article History: \\
\hline & Received : 14-02-2015 \\
\hline & Revised : :08-06-2015 \\
\hline & Accepted : 17-06-2015 \\
\hline & Keywords: \\
\hline & Banana \\
\hline & \\
\hline & Quality \\
\hline & \\
\hline & *Corresponding Author: \\
\hline & ıuliaz2006@yahoo.com \\
\hline
\end{tabular}

\section{INTRODUCTION}

Banana (Musa spp) is a climacteric fruit that shows marked physico-chemical changes during ripening. Banana ripening is very important aspect at commercial levels as the fruit is harvested at its green mature stage and subsequently induced to ripen artificially. Ethylene gas is synthesized by ripening bananas, but unripe fruit should be ripened by exposure to an exogenous source of ethylene gas for the assurance of firm pulp texture, good flavor and bright peel color (Robinson and Sauco, 2010). Under natural conditions, banana ripens slowly leading to high weight loss, uneven ripening and poor color development (Subbaiah et al., 2013).

Application of ethylene gas in ripening rooms or dipping fruits in ethylene releasing compounds such as ethrel are the most popular methods in large scale ripening. Extensive works have been done to study the effect of these methods on banana ripening and quality (Ahmad et al., 2006; Mahajan et al., 2010; Kulkarni et al., 2011; Subbaiah et al., 2013). As these techniques are relatively expensive to be used in developing countries like Ethiopia, bananas in most markets are ripened with traditional techniques. Local methods, such as keeping the fruits in sacks and in crates covered with hay, banana leaf and in plastic sheets are practiced by farmers and small traders (Berhe et al., 2010). Wholesalers in Ethiopia mainly ripen bananas in air tight rooms, smoked for 24 72 hours using kerosene burners. It is carried out mostly in small rooms, utilizing combustion of gases and high temperature generated by burning kerosene (Berhe et al., 2010). The smoke from kerosene burning is known to liberate ethylene with traces of other gases (Kulkarni et al., 2011).

Methods used to ripe bananas will have an impact on fruit quality and to the time required for ripening. However, there is little information as to what extent the local methods of ripening could influence the postharvest quality and shelf life of banana. The present study was initiated to investigate the effectiveness of ripening methods and evaluate their influence on postharvest quality of banana. 
Mulualem Azene Mebratie et al.,

\section{MATERIAL AND METHODS}

The study was conducted at the laboratory of the department of Food Science and Technology, Haramaya University, Ethiopia. The temperature and relative humidity of the storage rooms were recorded daily with digital thermo hygrometer. The average, maximum and minimum temperature was measured to be $24.54^{\circ} \mathrm{C}$, $26.8^{\circ} \mathrm{C}$ and $22.87^{\circ} \mathrm{C}$ while the relative humidity was $40.62 \%, 54.17 \%$ and $33.22 \%$, respectively. Average temperature of $27^{\circ} \mathrm{C}$ and relative humidity of $87.5 \%$ was recorded from the ripening room with smoke treatment.

\section{Experimental Materials and Treatments}

Banana (cv. Dwarf Cavendish) fruits were obtained from commercial farm around Arba Minch Zuria district, Gamo Gofa Zone, Southern Nations Nationalities and Peoples Region, Ethiopia. Fruits were harvested at green mature stage, graded and packed in plastic box and transported to Haramaya University (about $900 \mathrm{~km}$ distance) using canvas covered pick up. Five ripening treatments: dipping with ethephon, treating with smoke, keeping fruits in low density polyethylene (LDPE) plastic, in teff (Eragrostis tef) straw and banana leaf (control) were used as fruit ripening methods in this experiment. Treatments were randomly assigned to selected banana fruits kept in plastic crates. Bananas were dipped with ethephon solution (500 ppm) for five minutes and kept in ambient condition after air dried. For smoke treatment, bananas were kept in air tight room where kerosene burner was put on for $24 \mathrm{hr}$ and fruits were then held at ambient environment. On the other hand, bananas wrapped in LDPE plastic, covered with teff straw and those wrapped with banana leaf were put in plastic crates under ambient condition. Treatments were arranged in randomized complete block design with three replications each containing ten clusters of 6-7 fruits per cluster.

\section{Parameters Studied}

Physico-chemical qualities of banana fruits including color, firmness, physiological weight loss, pulp to peel ratio, total soluble solids, titratable acidity and marketability were determined at alternate days. Ripening period and shelf life were determined considering the changes in the physico-chemical qualities using five fruits randomly sampled from each replication.

Color of banana peel was visually determined using a standard color chart. A scale of 1 to 8 was used where: 1 is hard green, 2 is green with a trace of yellow, 3 is more green than yellow, 4 is more yellow than green, 5 is green tipped, 6 is fully yellow, 7 is yellow flecked with brown and 8 is browning and overripe (Collin and Dalnic, 1991). Pulp firmness of bananas was determined using a penetrometer (model FT 011; 0-11lbs) following the procedures of Dadzie and Orchard (1997). The pulp to peel ratio of bananas was determined by dividing pulp weight to the peel weight. Pulp and peel was separated, weighed and expressed as pulp to peel ratio (Dadzie and Orchard, 1997).

Physiological weight loss (PWL) was determined according to the methods described by Mohammed et al. (1999). Weight loss was calculated as the difference between initial and final weight in relative to initial fruit weight.

$$
W L(\%)=\frac{W_{i}-W_{f}}{W_{i}} \times 100
$$

Sci. Technol. Arts Res. J., April-June 2015, 4(2): 32-38

$$
\text { Where, } \begin{aligned}
W_{i} & =\text { initial weight } \\
W_{f} & =\text { final weight }
\end{aligned}
$$

The total soluble solids (TSS) of pulp juice were determined using a digital hand held refractometer (Palm Abbe $^{\mathrm{tm}}$ ) at $20{ }^{\circ} \mathrm{C}$ (Waskar et al., 1999). A $30 \mathrm{~g}$ of pulp tissue from the transverse section of the fruit was blended with $90 \mathrm{ml}$ distilled water for $2 \mathrm{~min}$ and filtered through a filter paper. A single drop of the filtrate was placed on the prism of a hand held refractometer and the percentage total soluble solids ( ${ }^{\circ}$ Brix) were recorded. The total titratable acidity (TA) of the pulp was determined by titration of the filtrate to the phenolphthalein end point and calculation of acid present as malic acid $(\mathrm{NaOH})$. A $25 \mathrm{ml}$ of the filtrate was transferred into a $125 \mathrm{ml}$ conical flask where $25 \mathrm{ml}$ of distilled water and 4 drops of phenolphthalein indicator were added and titrated with $0.1 \mathrm{~N}$ sodium hydroxide until the indicator just changes pink/red. Titratable acidity (\% malic acid) was calculated according to the following formula (Anthony et al. 2003).

$$
\mathrm{TA}(\%)=\frac{\text { Normalityof base } \mathrm{x} \text { volumeof base } \mathrm{x} .067 \mathrm{x} \text { dilutionfactor }}{\text { volumeof sample }} \times 100
$$

The percentage marketability of fruits was subjectively assessed according to the procedure described by Mohammed et al. (1999). The descriptive quality attributes was determined by observing the level of decay, color, surface defects, and shriveling. A 1 - 9 rating, considering 1 is unusable, 3 is unsalable, 5 is fair, 7 is good, and 9 is excellent, was used to evaluate the fruit quality. Bananas receiving a rating of 5 and above were considered marketable, while those rated less than 5 considered unmarketable. The percentage of marketable bananas was calculated as in the following formula.

Percentage marketability $=\frac{\text { Number of marketable banana fruit }}{\text { Total number of banana fruit }} \times 100$

Ripening period was determined based on the changes in color, firmness and TSS value of bananas (Dadzie and Orchard, 1997). Ripening period for fruits in each treatment was recorded as the number of days until fruit attain full ripe stage (color stage 6). Shelf life was assessed by visual inspection of fruits at alternate days; it was calculated as the period between commencement of ripening and end of marketable life (Dadzie and Orchard, 1997).

\section{Statistical Analysis}

Analysis of variance (ANOVA) for the parameters was done using SAS statistical software and comparison of the treatment means with significant difference was made by LSD test at $5 \%$ probability level.

\section{RESULTS AND DISCUSSION \\ Peel Color}

Banana peel color expressed as score (1-8 scale), started to show variation from day 2 and increased faster for smoke treated bananas followed by those treated with ethephon compared to other treatments (Figure 1). Bananas treated with smoke and ethephon reached a color score of 6 after 6 and 10 days, respectively, signifying that they reach the acceptable ripening level at different periods. Bananas ripened with teff straw and 
Mulualem Azene Mebratie et alo,

banana leaf attained color score of 6 with dull yellow color after 14 days implying slow ripening. Bananas ripened in low density polyethylene (LDPE) plastic showed reduced change in color with lower score, the highest value being 3.8 at the end of the storage life.

In addition to the presence of ethylene, increased temperature from kerosene heater might hasten the ripening process in smoke treatment. Similar results with respect to color change in smoke treated bananas (cv. Grand Naine) were reported by Subbaiah et al. (2013). Faster increases in color change were reported from smoke and ethephon (500 ppm) treated banana, the faster being from smoke treatment. The reduced change in color development of bananas in LDPE plastic might be
Sci. Technol. Arts Res. J., April-June 2015, 4(2): 32-38

due to the modified atmosphere and the higher humidity created resulting delay in the ripening rate. Polyethylene plastics are noted to have the effect of reducing water loss, reducing $\mathrm{O}_{2}$ concentration and increasing $\mathrm{CO}_{2}$, all of which extend the pre-climacteric life of fruits (Robinson and Sauco, 2010). A similar delay in development of yellow color was reported by Julianti et al. (2012) for bananas in LDPE plastic. The delay in color change of bananas from straw and banana leaf treatment might be attributed to the reduced humidity leading to higher moisture loss from the skin. According to Finger et al. (1995), excessive water loss from the fruit leads to reduced chlorophyll degradation. Similar features in color development were reported by Hailu et al. (2012) for bananas kept in teff straw and banana leaf.

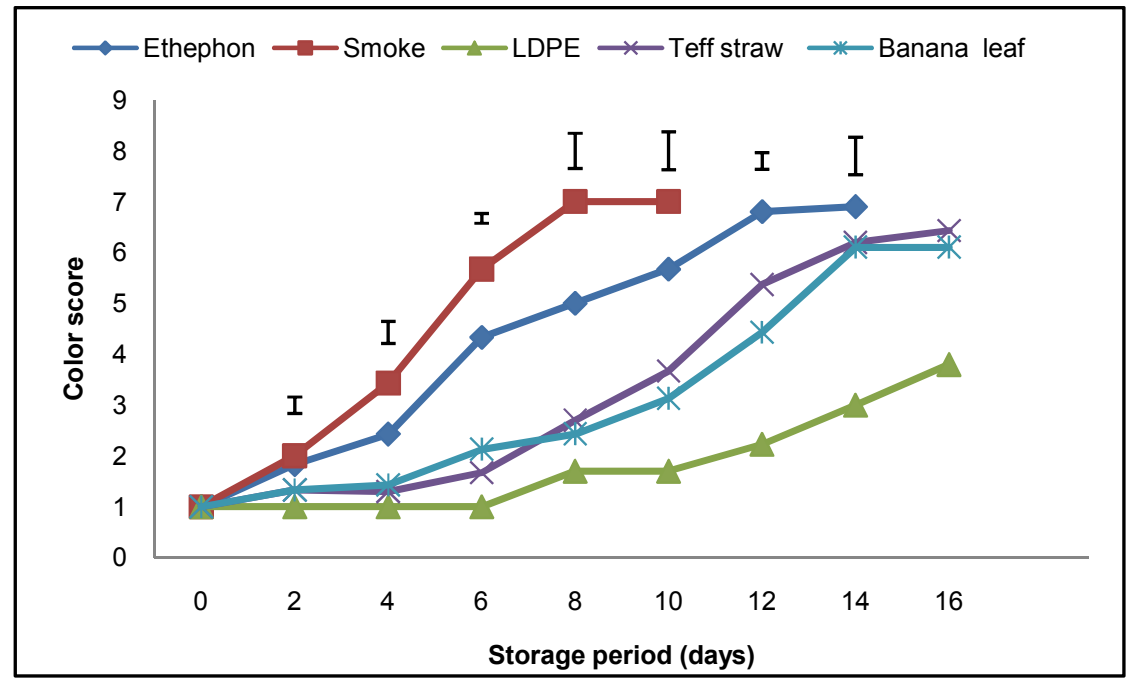

Figure 1: Changes in peel color of cv. Dwarf Cavendish bananas ripened at different conditions. LDPE: low density polyethylene plastic. The bar shows LSD at $P=0.05$.

\section{Firmness}

Banana pulp firmness showed a decreasing pattern while ripening advances, the change being faster for smoke treated bananas than in other treatments (Figure 2). Smoke treated bananas showed a drop in pulp firmness value to $1.72 \mathrm{~kg} \mathrm{~cm}^{-2}$ after 2 days storage while it was $4.58 \mathrm{~kg} \mathrm{~cm}^{-2}$ for ethephon treated and above $5 \mathrm{~kg} \mathrm{~cm}^{-}$ 2 for bananas in other treatments on the same day. Ethephon treated bananas were next to smoke treated bananas in decreasing pulp firmness. However, the decrease in pulp firmness was slow for bananas in teff straw and in banana leaf followed by fruits in LDPE plastic. The faster changes observed from the smoke and ethephon treatment might be as a result of enhanced ripening that leads to early softening. Fruit softening is associated with the processes of solubilization of pectic substances, break down of starch to soluble sugars and loss of water from peel (Turner, 2001; Kunasekaran, 2012). A similar decrease in pulp firmness was reported for bananas ripened with smoke and ethephon (500 ppm) treatments (Subbaiah et al., 2013). Hailu et al. (2012) also observed a relatively slower decrease in pulp softening of bananas kept in teff straw and in banana leaf than fruits kept in polyethylene plastic.

\section{Pulp to Peel Ratio}

Variation in pulp to peel ratio of bananas in different ripening treatments was observed from day 4 onwards (Figure 3). The faster change and higher values of pulp to peel ratio was observed from smoke treatment followed by ethephon treatment. A relatively slower change and lower values of pulp to peel ratio was observed for bananas kept in LDPE plastic, teff straw and banana leaf, the lowest being for bananas in LDPE plastic. The higher pulp to peel ratio for smoke and ethephon treated fruits might be due to the enhanced movement of water from peel to pulp as ripening advances while the reduced ripening of bananas in LDPE plastic, teff straw and banana leaf might be the reason for the slower change in pulp to peel ratio. Reduced water loss as a result of higher relative humidity might also be the other reason for the lowest pulp to peel ratio of bananas kept in LDPE plastic. Similar reports were presented by Hailu et al. (2012) for change in pulp to peel ratio of bananas kept in teff straw, banana leaf and LDPE plastic. Increase in pulp to peel ratio is related to water loss from the peel to the pulp and to the atmosphere. The faster increase in sugar content of the pulp leads to movement of water from pulp to the peel as result of osmotic differences (Dadzie and Orchard, 1997). 


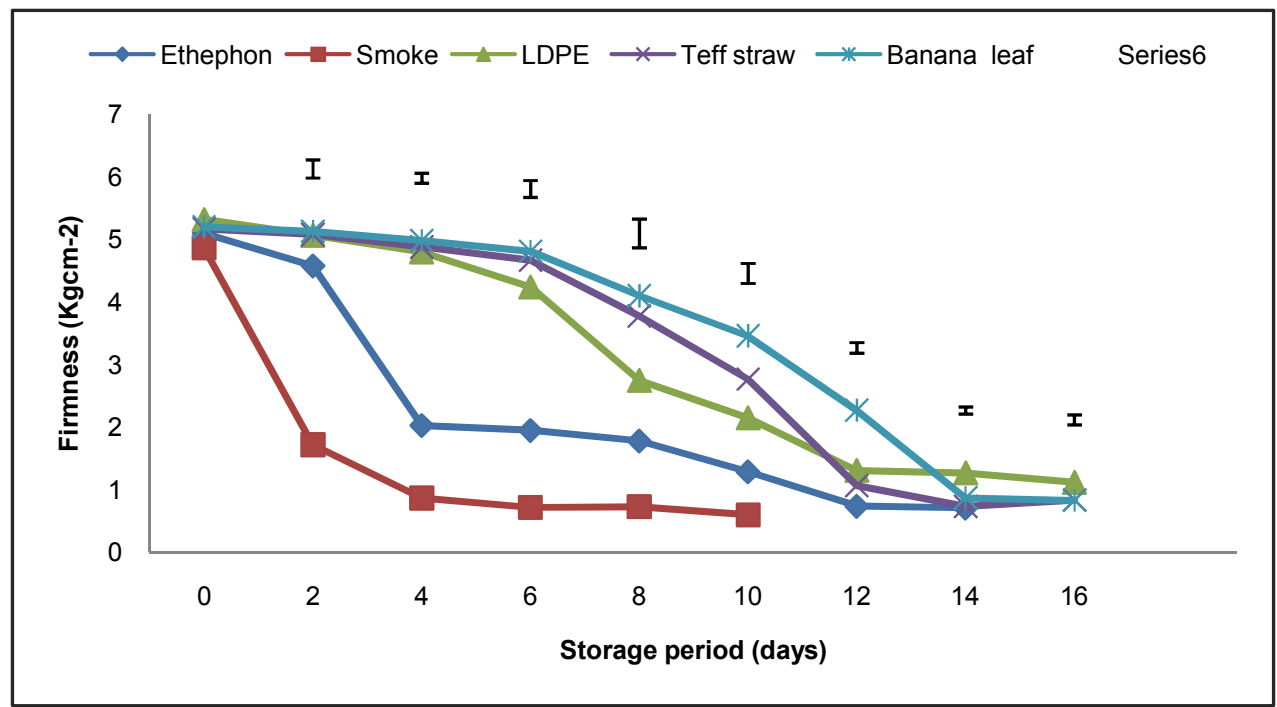

Figure 2: Changes in pulp firmness of cv. Dwarf Cavendish bananas ripened at different conditions. LDPE: low density polyethylene plastic. The bar shows LSD at $P=0.05$.

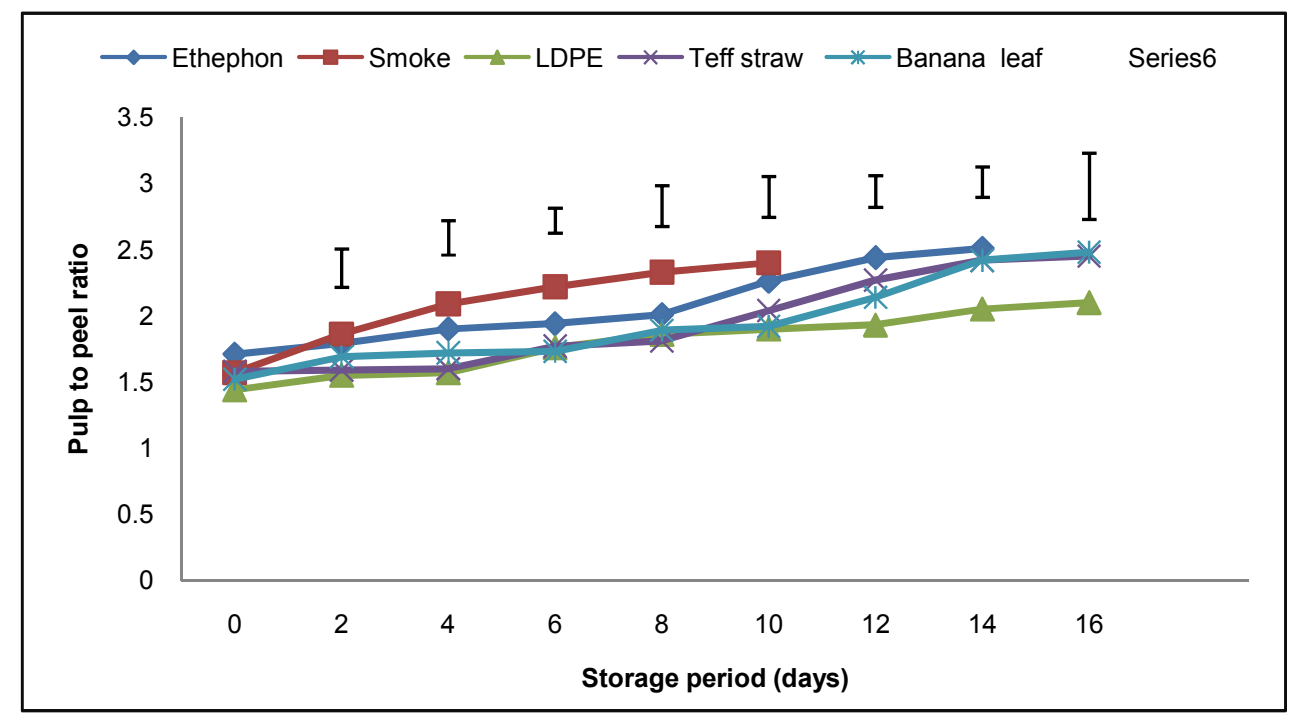

Figure 3: Change in pulp to peel ratio of cv. Dwarf Cavendish bananas ripened at different conditions. LDPE: low density polyethylene plastic. The bar shows LSD at $P=0.05$.

\section{Physiological Weight Loss}

A progressive increase in physiological weight loss $(P W L)$ was observed for bananas from all ripening treatments (Figure 4). However, LDPE plastic resulted in the lowest PWL while smoke treatment followed by ethephon treatment resulted in the highest PWL throughout the storage period. Bananas from smoke and ethephon treatments lost more than $13 \%$ of their weight on day six while bananas in LDPE plastic lost only $5.12 \%$ after 16 days of storage. Bananas in teff straw followed by bananas in banana leaf also resulted in a higher PWL as compared to bananas in LDPE plastic. The reduced weight loss of bananas in LDPE plastic might be due to lower transpiration rate in a higher relative humidity environment as well as reduced respiration due to gradual decline in $\mathrm{O}_{2}$ and increase of $\mathrm{CO}_{2}$ in the plastic. However, enhanced water loss as a result of increased transpiration and respiration rate might be the reason for increased in PWL of smoke and ethephon treated bananas. Results related to this were also reported by Hailu et al. (2012) for
PWL of bananas kept in polyethylene plastic, teff straw and banana leaf.

\section{Total Soluble Solids}

Ripening treatments resulted in a significant $(P \leq$ 0.001 ) variation in total soluble solid (TSS) content of bananas. Smoke treatment resulted in the highest TSS values during most of the storage periods followed by ethephon treatment indicating earlier ripening of fruits exposed to ethylene (Figure 5). The TSS value of smoke treated fruits rapidly increased to $10.1 \%$ on day 2 reaching its peak value of $17.9 \%$ after 8 days of storage. A similar rapid increase in TSS to $10.5 \%$ after 4 days, attaining peak value (18.3\%) after 12 days was observed for ethephon treated bananas. The change in TSS content was relatively slow for bananas in LDPE plastic, teff straw and banana leaf and reached a maximum of $12.7 \%$, $16.1 \%$ and $15.4 \%$ after 14,16 and 16 days of storage, respectively. 


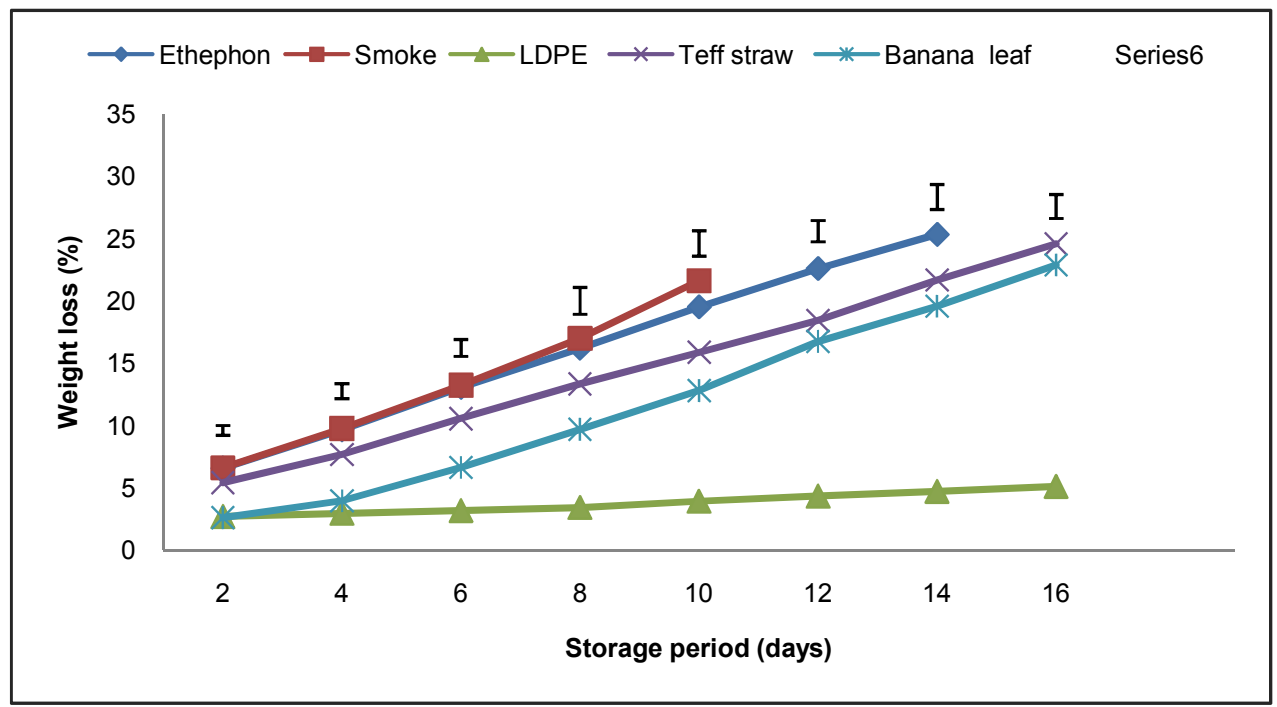

Figure 4: Change in percent physiological weight loss of cv. Dwarf Cavendish bananas ripened at different conditions. LDPE: low density polyethylene plastic. The bar shows LSD at $P=0.05$

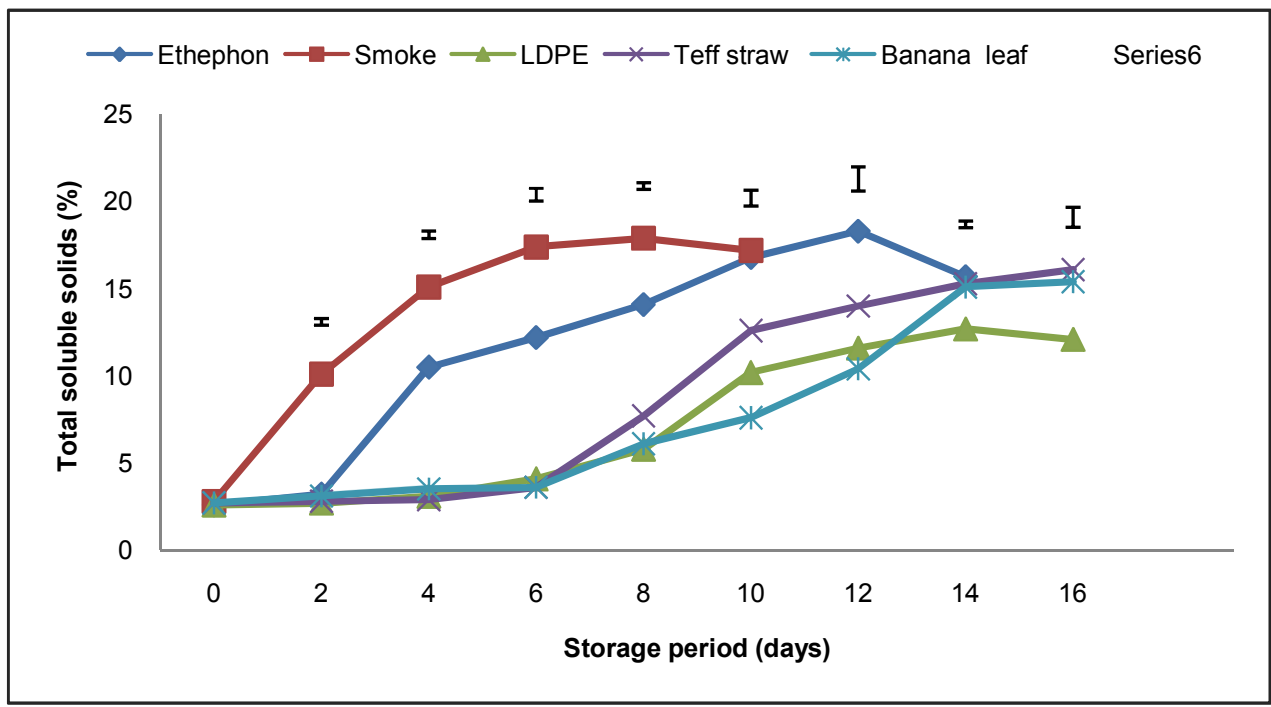

Figure 5: Change in total soluble solids content of cv. Dwarf Cavendish bananas ripened at different conditions. LDPE: low density polyethylene plastic. The bar shows LSD at $P=0.05$

The faster change observed in TSS value of smoke and ethephon treated bananas from the present study might be attributed to enhanced ripening rate as a result of exogenous ethylene source. Furthermore, the heat generated from smoking process might hasten the ripening rate and hydrolysis of starch more in smoke treated bananas. On the other hand, the absence of external ethylene source and reduced internal ethylene production for bananas in other treatments might be the reason for reduced TSS value and ripening related changes. Changes in the TSS content of bananas could be attributed to the breakdown of starch into simple sugars during the ripening process (Dadzie and Orchard, 1997). Similar increase in TSS of bananas during ripening was reported by Kulkarni et al. (2010) and Hailu et al. (2012).

\section{Titratable Acidity}

A significant variation in titratable acidity (TA) of bananas ripened differently was observed from day 2 onwards. A faster rate in change and higher TA values was observed for smoke treated bananas followed by ethephon treated bananas (Figure 6). Smoke treated bananas showed a rapid increase in TA on day 2 and attained peak value of $0.45 \%$ on day 4 while ethephon treated bananas wrapped in banana leaf scored peak values on day $6(0.45 \%)$ and $12(0.37 \%)$, respectively. Peak values of TA for bananas in LDPE plastic and teff straw were observed on day 8 and 10 , respectively. The faster increase in TA value of bananas from smoke treatment and ethephon treatment might be as a result of the enhanced ripening in the two treatments.

\section{Marketability}

Marketability of banana fruits from all the ripening treatments was maintained at $100 \%$ up to day 8 of the storage period (Figure 7). However, smoke treated bananas showed a drop in their marketability to $38.67 \%$ on day 10 while fruits marketability in other treatments was above $83 \%$. 


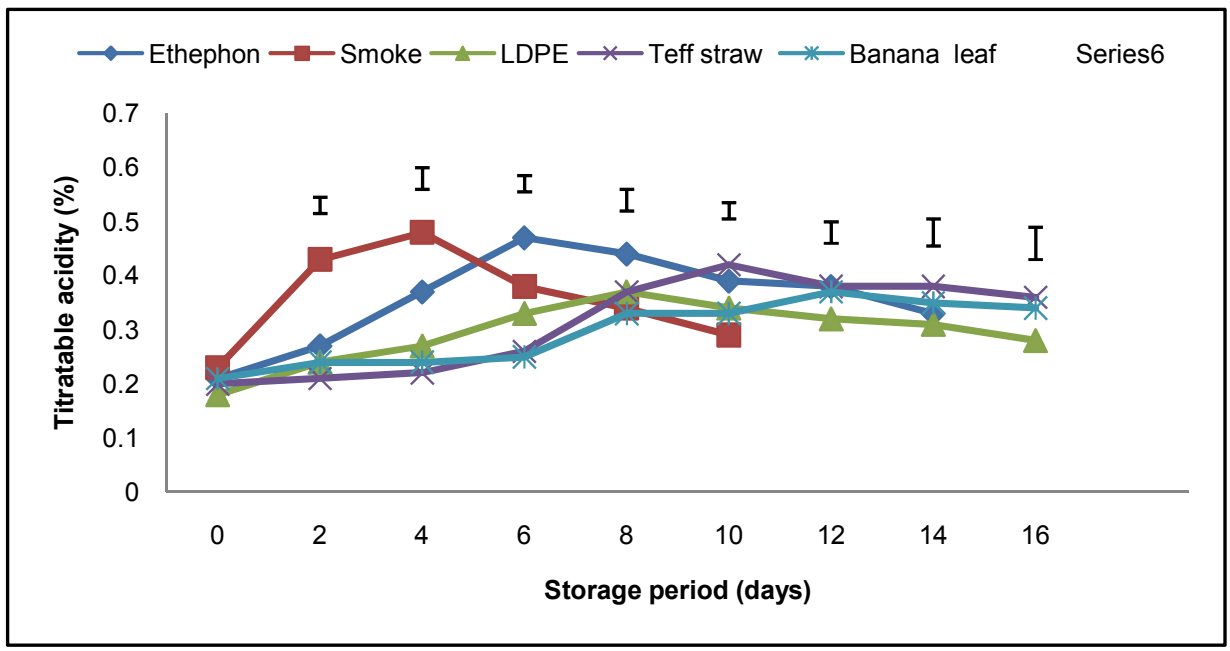

Figure 6: Change in titratable acidity value of cv. Dwarf Cavendish bananas ripened at different conditions. LDPE: low density polyethylene plastic. The bar shows LSD at $P=0.05$

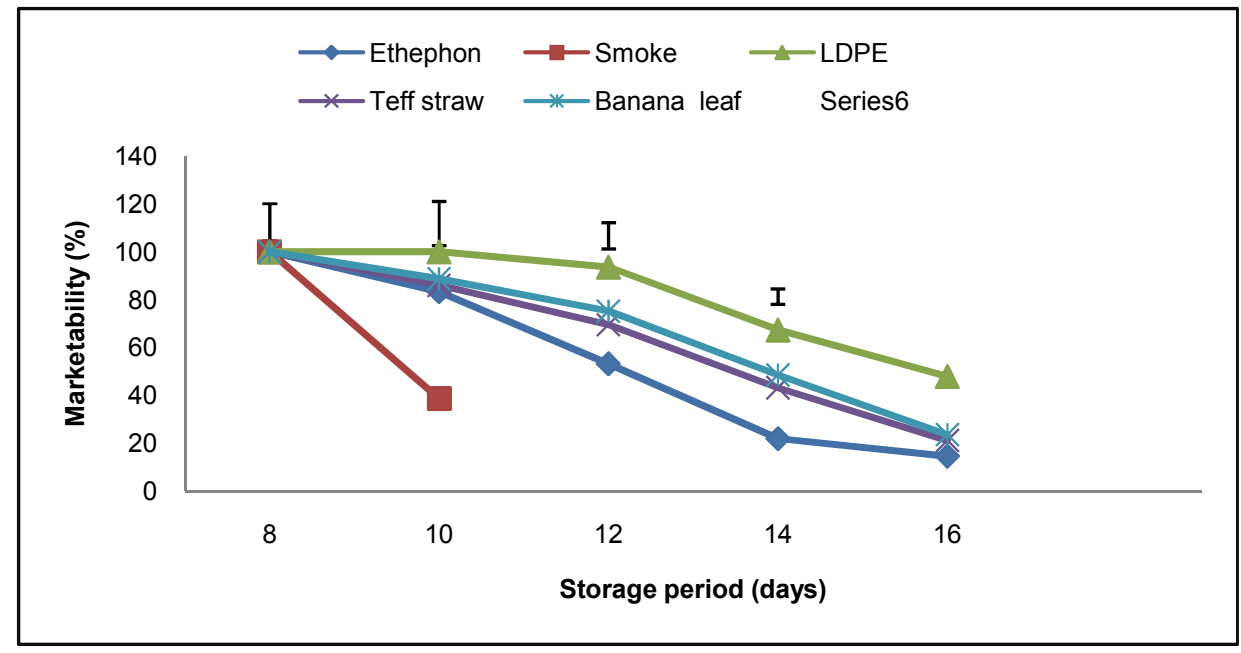

Figure 7: Percentage marketability of cv. Dwarf Cavendish bananas ripened at different conditions. LDPE: low density polyethylene plastic. The bar shows LSD at $P=0.05$

Marketability of bananas ripened with ethephon, teff straw and banana leaf reduced to less than $50 \%$ on day 14 while it was on day 16 for bananas in LDPE plastic. Blackening and softening as a result of over ripening were the main reasons for loss in marketability of smoke and ethephon treated bananas while decay and failure to degreening were the main causes for loss in marketability of bananas kept in LDPE plastic. Bananas in teff straw and in banana leaf were mainly unmarketable because of shriveling and browning as a result of water loss. The faster reduction in marketability of smoke treated bananas might be because of increased respiration rate in fruits enhanced by higher temperature from the smoking process. Hailu et al. (2012) reported similar results for the loss in marketability of bananas kept in teff straw and banana leaf.

\section{Days to Ripe and Shelf Life}

Ripening methods resulted in a significant $(P \leq 0.001)$ variation on days to fully ripe stage of bananas. Bananas from the smoke treatment attained fully ripe stage within 6 days while bananas from ethephon treatment attained the same stage after 10 days storage (Table 1). Whereas, bananas in the LDPE plastic reach to full ripe stage in 13 days storage, bananas in teff straw and those in banana leaf came to this stage in 14 days storage indicating slow ripening process. No significant difference in color at fully ripe stage score was observed for bananas from all the ripening treatments, except for the case of LDPE plastic. Smoke treatment resulted in similar fruit qualities (color and TSS) with no significant difference from that of ethephon treatment except smoke treated bananas were softer like fruits ripened in teff straw and banana leaf. No significant difference in quality at fully ripe stage was also observed between fruits ripened in teff straw and banana leaf. Both ripening with ethephon and ripening with LDPE plastic resulted in the highest shelf life of 10 days while the shelf life for smoke ripened bananas was 8 day, with no significant difference in shelf life to fruits ripened with teff straw and banana leaf.

Exogenous ethylene application as in the case of smoke and ethephon treatments might enhance the physico-chemical changes shortening the time to reach fully ripe stage, the process also being faster by increased temperature from the smoke treatment. Thus, the shorter shelf life of smoke treated bananas was possibly due to the accelerated physico-chemical changes. On the other. 
Table 1: Effect of ripening methods on ripening period and shelf life of cv. Dwarf Cavendish bananas

\begin{tabular}{cccccc}
\hline \multirow{2}{*}{ Ripening } & $\begin{array}{c}\text { Ripening period } \\
\text { (days) }\end{array}$ & \multicolumn{3}{c}{ Qualities at fully ripe stage } & $\begin{array}{c}\text { Shelf life } \\
\text { (days) }\end{array}$ \\
\cline { 3 - 5 } & $10.0^{\mathrm{c}}$ & Color & Firmness & TSS & \\
Ethephon & $6.0^{\mathrm{a}}$ & $5.67^{\mathrm{a}}$ & $1.29^{\mathrm{a}}$ & $16.80^{\mathrm{a}}$ & $10.0^{\mathrm{a}}$ \\
Smoke & $12.7^{\mathrm{b}}$ & $2.23^{\mathrm{b}}$ & $1.31^{\mathrm{a}}$ & $17.40^{\mathrm{a}}$ & $8.0^{\mathrm{b}}$ \\
LDPE plastic & $14.0^{\mathrm{a}}$ & $6.20^{\mathrm{a}}$ & $0.74^{\mathrm{b}}$ & $15.30^{\mathrm{b}}$ & $10.0^{\mathrm{a}}$ \\
Teff straw & $14.0^{\mathrm{a}}$ & $6.10^{\mathrm{a}}$ & $0.87^{\mathrm{b}}$ & $15.10^{\mathrm{b}}$ & $8.0^{\mathrm{b}}$ \\
Banana leaf (control) & 4.56 & 6.33 & 9.10 & 3.10 & 5.78 \\
\hline CV & 0.82 & 0.40 & 0.07 & 0.55 & 0.27 \\
\hline SE & &
\end{tabular}

TSS: total soluble solids; LDPE: low density polyethylene; CV: coefficient of variation; SE: standard error; means followed by the same letter in a column are not significantly different at $P<0.05$ (LSD test).

Shelf life was calculated as the period (in days) betweencommencement of ripening and end of salable life.

hand, the longer shelf life of bananas in LDPE plastic might be due to the delayed ripening process as a result of a relatively higher humidity in the plastic and change in composition of air. Related results were presented for reduced ripening and increased shelf life of bananas kept in a higher relative humidity environment (Ullah et al., 2006). The reduced shelf life of smoke treated fruits is also in agreement with the previous findings of Maerere et al. (2008) who reported shorter shelf life of less than 8 days for smoke treated bananas (Grand Naine) as compared to ethephon treated and naturally ripened bananas

\section{CONCLUSIONS}

The experiment showed that smoking and ethephon application enhanced the ripening process considerably than ripening with no exogenous ethylene source. Smoke treatment resulted in the shortest ripening period of 6 days without affecting the measurable ripening qualities of banana. Similar results in fruit quality were observed at fully ripe stage with ethephon treated bananas except for shorter shelf life (8 days) in case of smoke treated fruits. Thus, ethephon treatment showed better result in terms of fruit quality, shelf life and marketability of ripened bananas. Smoke treatment also resulted in a rapid ripening process, with no considerable undesirable effect on banana quality but with reduced shelf life. Working on ways of reducing temperature from the smoking process could improve the efficiency of smoke treatment enabling early ripening and longer shelf life to bananas which can make it an available alternative where other commercial ethylene sources are unavailable.

\section{Acknowledgement}

The authors are thankful for the financial support from Swedish International Development Cooperation AgencyHaramaya University (SIDA-HU) research fund. The authors are also grateful to the laboratory assistants of the department of Food Science and Technology and horticulture program of Haramaya University.

\section{Conflict of Interest}

All the authors declared no conflict of interest.

\section{REFERENCES}

Ahmed, S., Thompson, A.K., Perviez, M.A., Ullah, H., Chatha, Z.A. (2006). Effect of polyethylene film thickness and exposure time of ethylene on the ripening behavior and quality of banana. International Journal of Agriculture and Biology 8(3): 381-386.

Berhe, K., Puskur, R., Teka, W., Hoekstra, D., Tegegne, A. (2010). Innovation in banana value chain development in Metema district, northwestern Ethiopia: Improving productivity and market success (IPMS) project experiences. Acta Horticulturae 879:129-139.

Dharmasena, D.A.N., Kumari, A.H.M.R.R. (2005). Suitability of charcoal-cement passive evaporative cooler for banana ripening. Journal of Agricultural Sciences 1(1): 19-30.

Finger, F.L., Puschmann, R. Raimundo, S.B. (1995). Effects of water loss on respiration, ethylene production and ripening of banana fruit. Brazilian Journal of Plant Physiology 7(1): 115-118.

Julianti, E., Ridwansyah, Yusraini, E. (2012). Effect of modified atmosphere packaging on postharvest quality of barangan banana. Journal of Food Science and Engineering 2(1): 39-44.

Kulkarni, S.G., Kudachikar, V.B., Prakash, M.K. (2011). Studies on physico-chemical changes during artificial ripening of banana (Musa spp) variety 'Robusta'. Journal of Food Science and Technology 48(6): 730-734.

Kunasekaran, W., Boyce, A.N., Chandran, S. (2012). Cell wall degrading enzyme activities during ripening in 'Nangka' (AAB) Bananas. Acta Horticulturae. 943:103-10.

Maerere A.P., Munubi, R., Mgembe, E.R. (2008). Effects of harvesting stage and smoke ripening on the time to ripening, shelf life and quality of dessert banana. IITA, Banana and plantain in Africa: Harnessing international partnerships to increase research impact. October 5-9, Mombasa, Kenya.

Mahajan, B.V.C., Kaur, T., Gill, M.I.S., Dhaliwal, H.S., Ghuman, B.S., Chahil, B.S. (2010). Studies on optimization of ripening techniques for banana. Journal of Food Science and Technology 47(3): 315-319.

McGlone, V.A., Kawano, S. (1998). Firmness, dry matter and soluble solids assessment of postharvest kiwifruit by NIR spectroscopy. Postharvest Biology and Technology 13: 131-141.

Robinson, J.C., Sauco, V.G. (2010). Bananas and Plantains. $2^{\text {nd }}$ ed. CAB International, UK, MPG Books, pp 259-263.

Subbaiah, K.V., Jagadeesh, S.J., Thammaiah, N., Chavan, M.L. (2013). Changes in physico-chemical and sensory characteristics of banana fruit cv. Grand Naine during ripening. Karnataka Journal of Agricultural Sciences 26 (1): 111-114.

Ullah, H., Ahmad, S., Anwar, R., Thompson, A.K. (2006). Effect of high humidity and water on storage life and quality of bananas. International Journal of Agriculture and Biology 8(6): 828-831.

Waskar D.P., Khedkar R.M., Garande, V.K. 1999. Effect of postharvest treatments on shelf life and quality of pomegranate in evaporative cool chamber and ambient conditions. Journal of Food Science and Technology 36(2): 114-117. 